\title{
Mosaicism in preimplantation human embryos
}

\author{
A. F. Saifitdinova ${ }^{\boxplus 1,2}$, O. S. Glotov ${ }^{3,4}$, I. V. Poliakova ${ }^{3}$, N. K. Bichevaya ${ }^{2}$, Ju. A. Loginova ${ }^{5}$, \\ R. A. Kuznetsova ${ }^{2}$, O. A. Leonteva ${ }^{2}$, E. E. Nevskaia'2, O. A. Pavlova ${ }^{2,6}$, I. L. Puppo ${ }^{7,2}$, \\ A. E. Shikov', S. P. Urazov ${ }^{3}$, T. V. Kuznetzova ${ }^{4}$, A. M. Sarana ${ }^{8}$, S. G. Scherbak ${ }^{3}$, V. S. Baranov ${ }^{4}$
}

\author{
${ }^{1}$ Herzen State Pedagogical University of Russia, 48 Moika River Emb., Saint Petersburg 191186, Russia \\ ${ }^{2}$ International Centre for Reproductive Medicine, 53/1 Komendantskij Ave., Saint Petersburg 197350, Russia \\ ${ }^{3}$ City Hospital No. 40, 9 Borisova Str., Sestroretsk, Saint Petersburg 197706, Russia \\ ${ }^{4}$ The Research Institute of Obstetrics, Gynecology and Reproductology named after D. O. Ott, \\ 3 Mendeleevskaya Line, Saint Petersburg 199034, Russia \\ ${ }^{5}$ DiaCarta, Inc, 2600 Hilltop Drive, Richmond, CA 94806, USA \\ ${ }^{6}$ Customer Laboratory Service Associate, Beagle Ltd., 152/1 Bukharestskaya Str., \\ Saint Petersburg 192289, Russia \\ ${ }^{7}$ Almazov National Medical Research Centre of the Ministry of Health of the Russian Federation, \\ 2 Akkuratova Str., Saint Petersburg 197341, Russia \\ ${ }^{8}$ Saint Petersburg State University, 7/9 Universitetskaya Emb., Saint Petersburg 199034, Russia
}

\author{
Authors \\ Alsu F. Saifitdinova, SPIN: 5114-4844, \\ Scopus AuthorID: 6603195889, \\ ORCID: 0000-0002-1221-479X, \\ e-mail: saifitdinova@mail.ru \\ Oleg S. Glotov, SPIN: 4531-3449, \\ Scopus AuthorID: 23988449900, \\ ORCID: 0000-0002-0091-2224, \\ e-mail: olglotov@mail.ru \\ Irina V. Poliakova, SPIN: 2362-7626, \\ Scopus AuthorID: 55371136300, \\ ORCID: 0000-0002-5738-8443, \\ e-mail: irena.88@inbox.ru \\ Natalia K. Bichevaya, \\ ORCID: 0000-0001-8866-5821, \\ e-mail: bichevaya@mcrm.ru \\ Julia A. Loginova, SPIN: 9532-4407, \\ Scopus AuthorID: 55597320200, \\ ORCID: 0000-0002-1304-5967, \\ e-mail: j.a.loginova@gmail.com \\ Rena A. Kuznetsova, \\ ORCID: 0000-0003-4195-6968, \\ e-mail: kuznetsova@mcrm.ru \\ Olga A. Leonteva, \\ ORCID: 0000-0002-3667-0511, \\ e-mail: olga leont@mail.ru \\ Elizaveta E. Nevskaia, \\ ORCID: 0000-0003-0626-6048, \\ e-mail: elizaveta.nevsk@yandex.ru \\ Olga A. Pavlova, SPIN: 1366-7591, \\ ORCID: 0000-0001-9488-6903, \\ e-mail: beagle07@bk.ru \\ Irina L. Puppo, SPIN: 3817-9200, \\ Scopus AuthorID: 55201398200, \\ ORCID: 0000-0001-8538-3845, \\ e-mail: il_trofimova@list.ru
}

Abstract. Since the very first publications on preimplantation genetic testing, researchers have faced a serious problem - a high mosaicism level in the preimplantation human embryos obtained by means of in vitro fertilization cycles. The nature of this mosaicism and its high impact on embryo development draws attention to this issue. In this research we studied the cells from different parts of preimplantation human embryos with mosaicism in the trophectoderm cells detected using Next-generation Sequencing (NGS). Six human blastocysts with mosaicism in their trophectoderm cells were each sectioned in three parts: two containing only trophectoderm cells and one predominantly inner cell mass. These parts were then analyzed individually. Our data indicate that the proportion of aneuploid cells in bioptate taken for preimplantation genetic testing does not necessarily reflect the true chromosomal status of the whole embryo and cannot be extrapolated to that in the embryoblast cells. The results of our study strongly suggest that mosaicism revealed in blastocyst reduces the likelihood of finding the euploid chromosome set in the other parts of the embryo. Karyotypes of cells from different parts of mosaic embryos show low concordance. Chromosomal abnormalities in mosaic embryos are unpredictably diverse, which may lead not only to loss of conception, but also to the development of genetic disease in the offspring. According to our data, the mosaic rate tends to increase in the samples containing trophectoderm adjacent to the embryoblast, which may have physiological significance for the implantation. Comparative studies focused on the concordance of mosaicism level of and the type of chromosomal abnormalities detected in different parts of preimplantation human embryos will improve clinical recommendations regarding the transfer of mosaic embryos.

Keywords: mosaicism, human embryos, aneuploidy, preimplantation genetic testing, in vitro fertilization. 


\author{
Anton E. Shikov, \\ Scopus AuthorID: 57210888268, \\ ORCID: 0000-0001-7084-0177, \\ e-mail: antonshikov96@gmail.com \\ Stanislav P. Urazov, SPIN: 7280-8107, \\ Scopus AuthorID: 57203680120, \\ ORCID: 0000-0002-5441-2911, \\ e-mail: urasta@list.ru \\ Tatyana V. Kuznetzova, SPIN: 1000- \\ 7522, ORCID: 0000-0003-1738-6782, \\ e-mail: tkuznetzova@mail.ru \\ Andrei M. Sarana, SPIN: 7922-2751, \\ ORCID: 0000-0003-3198-8990, \\ e-mail: asarana@mail.ru \\ Sergei G. Scherbak, SPIN: 1537-9822, \\ ORCID: 0000-0001-5047-2792, \\ e-mail: sgsherbak@mail.ru \\ Vladislav S. Baranov, \\ SPIN: 9196-7297, \\ Scopus AuthorID: 56057974100, \\ ORCID: 0000-0002-6518-1207, \\ e-mail: baranov@vb2475.spb.edu \\ For citation: Saifitdinova, A. F., \\ Glotov, O. S., Poliakova, I. V., \\ Bichevaya, N. K., Loginova, Ju. A., \\ Kuznetsova, R. A., Leonteva, O. A., \\ Nevskaia, E. E., Pavlova, O. A., \\ Puppo, I. L., Shikov, A. E., \\ Urazov, S. P., Kuznetzova, T. V., \\ Sarana, A. M., Scherbak, S. G., \\ Baranov, V. S. (2020) Mosaicism \\ in preimplantation human embryos. \\ Integrative Physiology, vol. 1, no. 3, \\ pp. $225-230$. DOI: $10.33910 / 2687-$ \\ 1270-2020-1-3-225-230 \\ Received 29 November 2019; \\ reviewed 30 December 2019; \\ accepted 15 January 2020. \\ Funding: The study was supported \\ by the fundamental theme of research \\ No. AAAA-A19-119021290033-1. \\ Copyright: (C) The Authors (2020). \\ Published by Herzen State \\ Pedagogical University of Russia. \\ Open access under CC BY-NC \\ License 4.0.
}

\section{Introduction}

Postzygous mitotic errors might result in cell clones with unequal chromosomal sets within the same embryo. This phenomenon has been described as embryonic mosaicism. Mosaicism should be considered thoroughly when being examined in preimplantation embryos at blastocyst stage. Numerous data estimate relatively high mosaicism frequency in blastocyst (Weissman et al. 2017). Meanwhile, mosaicism of trophectoderm (TE) cells does not necessarily correspond to the one within the inner cell mass (ICM) (Munné et al. 2017). This fact can significantly complicate the interpretation of preimplantation genetic testing (PGT) results.
The observation that mosaicism in preimplantation human embryos is often identified in vitro fertilization cycle with preimplantation genetic testing for aneuploidy (PGT-A) raises the inevitable question of how a mosaicism level can be reliably estimated. Rapid advancement of Next-generation Sequencing (NGS) in conjunction with a single cell whole genome amplification techniques have stimulated implementation of this approach for PGT-A. The high sensitivity of the NGS method enables researchers to identify with high confidence the mosaicism in TE DNA samples with a single abnormal cell ( $20 \%$ for samples with 5 cells). With the NGS approach it has been shown that mosaicism frequency in preimplantation blastocysts varies 
from $17 \%$ to $47 \%$ in nine diverse artificial reproductive technology (ART) centres (Sachdev et al. 2016). Nevertheless, the available comparative data on chromosomal mosaicism values in TE and ICM cells remains limited and controversial (Munne et al. 2017).

Thus, maintaining the efficiency of ART requires additional investigation of mosaicism. The principal goal of the present paper is to discuss the application of NGS-techniques in evaluating the mosaicism level in diverse cell fractions of preimplantation human embryos with TE mosaicism detected earlier by PGT-A.

\section{Materials and methods}

All procedures were fulfilled according to the World Medical Association's Declaration of Helsinki. The Scientific Review Board of the Research Institute of Obstetrics, Gynecology and Reproductology named after D. O. Ott approved the research and endorsed the fundamental research topic No. AAAA-A19-119021290033-1. Informed consent was obtained from all healthy voluntary participants, who provided gametes for the research. Early human embryos were obtained by artificial insemination by means of intracytoplasmic sperm injection procedure. Oocytes from 16 clinically healthy fertile voluntary participants at the age of 2032 years with a normal karyotype were fertilized in vitro with sperm from 11 clinically healthy donors with a normal karyotype from the International Centre for Reproductive Medicine (ICRM) sperm bank according to the published protocol (Korsak et al. 2019). Pronuclei and polar bodies were checked 16-18 hours after fertilization. Embryos were cultured in sequential culture media solutions (COOK) for 5-6 days up to blastocyst stage. The latter were examined and graded in accordance with Gardner classification (Gardner, Schoolcraft 1999). High quality blastocysts were subjected to TE biopsy and cryopreserved by vitrification in Kitazato medium according to recommended protocol (Kitazato Supply Co., Fujinomiya, Japan).

PicoPLEX whole genome amplification (WGA) Kit (Rubicon Genomics) was used for whole genome amplification. The concentration of WGA products was measured with Quantus ${ }^{\mathrm{TM}}$ Fluorometer (Promega) and QuantiFluor ${ }^{\circledR}$ dsDNA System reaction kit. DNA libraries were prepared according to VeriSeq PGS kit (Illumina) and assessed for quality with TapeStation 4200 (Agilent). Sequencing of the libraries was performed on Illumina MiSeq. Numerical chromosome abnormalities analysis was carried out in BluFuse Multi v4.3 (Illumina) software. This method provides effective resolution of $20 \mathrm{Mb}$.
Embryos with detected single or multiple chromosomal mosaicism in TE cells were thawed and incubated until complete expansion. Such blastocysts were sectioned in three parts with two containing TE cells and one - predominantly with ICM cells as previously described (Taylor et al. 2016). WGA, sequencing, and qualitative DNA evaluation were performed for each sample as indicated above.

\section{Results and discussion}

After morphological evaluation blastocysts of high quality were subjected to TE biopsy for PGT-A by NGS technique and cryopreserved. Six blastocysts in which TE cells mosaicism was observed were thawed and analyzed further (Table 1).

Embryo 492x94 e5 (No. 1) was characterized by mosaic monosomy for chromosome 16 as indicated by PGT-A. Non-mosaic monosomy 16 was detected in the other two TE sites, however, in ICM it was also detected in mosaic state. Presumably the monosomy 16 had occurred during meiosis and in some cells reduplication restored chromosome set to euploid state. Mosaicism for trisomy of chromosome 1 was detected in a sample containing ICM. It is most likely that trisomy 1 emerged during the cleavage stage, given that monosomy 16 and especially trisomy 1 are not found during prenatal stage.

Embryo 500x97 e15 (No. 2) demonstrated mosaic trisomy for chromosome 8 as detected by PGT-A. However, when analyzing cells from other sites, not only monosomy 8 , but also trisomy 8 , trisomy 3 , monosomy 10 , and $\mathrm{X}$ and $\mathrm{Y}$ aneuploidy were found. All these anomalies most probably resulted from mitotic nondisjunction during cleavage. The presence of reciprocal mosaic aneuploidy on chromosome 8 can indirectly point to this. The transfer of this embryo could result in pregnancy loss during the first trimester with the high probability, as autosomal monosomy and $\mathrm{X}$ nullisomy are lethal, and trisomy 3 in the placenta leads to complicated pregnancy whereas trisomy 8 by itself is responsible for $0.7 \%-0.8 \%$ of all spontaneous abortions (Campbell et al. 2001). Mosaic trisomy 8 is compatible with embryonic development and live birth. The prognosis for embryos with the male set of sex chromosomes (XY) is more negative, as they are more likely to be born since the ratio of newborn girls to boys with this syndrome is 1:5 (Gardner, Amor 2018).

Embryo 590x77 e2 (No. 3) was marked by chromosome 6 monosomy in the first sample and trisomy 6 in the ICM+TE sample. Reciprocal mosaic aneuploidy for chromosome 6 , as in the previous case No. 2), may arise from chromosome nondisjunction of euploid cell during the cleavage stage. 
Table 1. Molecular genetic study of embryos with detected TE mosaicism

\begin{tabular}{|c|c|c|c|c|c|c|}
\hline № & $\begin{array}{l}\text { Embryo } \\
\text { barcode }\end{array}$ & $\begin{array}{l}\text { Embryo } \\
\text { quality }\end{array}$ & Analysis type & $\begin{array}{l}\text { Number } \\
\text { of cells }\end{array}$ & $\begin{array}{c}\text { Detected chromosomal } \\
\text { anomaly }\end{array}$ & $\begin{array}{c}\text { Percent } \\
\text { of abnormal cells }\end{array}$ \\
\hline \multirow[t]{5}{*}{1} & \multirow[t]{5}{*}{$492 \times 94$ e5 } & $\mathrm{Bl} 3 \mathrm{AB}$ & PGT-A & 5 & Monosomy 16 & 80 \\
\hline & & \multirow[t]{4}{*}{ HBl3AB } & TE 1 & 7 & Monosomy 16 & $100 \%$ \\
\hline & & & TE 2 & 7 & Monosomy 16 & $100 \%$ \\
\hline & & & \multirow{2}{*}{$\mathrm{ICM}+\mathrm{TE}$} & \multirow[t]{2}{*}{10} & Trisomy 1 & $40 \%$ \\
\hline & & & & & Monosomy 16 & $80 \%$ \\
\hline \multirow[t]{9}{*}{2} & \multirow[t]{9}{*}{$500 \times 97$ e15 } & Bl3AA & PGT-A & 5 & Trisomy 8 & $40 \%$ \\
\hline & & \multirow[t]{8}{*}{ HBl6AA } & \multirow[t]{3}{*}{ TE 1} & \multirow[t]{3}{*}{10} & Trisomy 3 & $50 \%$ \\
\hline & & & & & Trisomy 8 & $50 \%$ \\
\hline & & & & & $\mathrm{XYY}$ & $10 \%$ \\
\hline & & & \multirow[t]{2}{*}{ TE 2} & \multirow[t]{2}{*}{7} & Monosomy 8 & $40 \%$ \\
\hline & & & & & Nullisomy X, Y & $10 \%$ \\
\hline & & & \multirow[t]{3}{*}{$\mathrm{ICM}+\mathrm{TE}$} & \multirow[t]{3}{*}{10} & Monosomy 8 & $40 \%$ \\
\hline & & & & & Monosomy 10 & $20 \%$ \\
\hline & & & & & $\mathrm{XYY}$ & $10 \%$ \\
\hline \multirow[t]{7}{*}{3} & \multirow[t]{7}{*}{$590 \times 77$ e2 } & Bl3AA & PGT-A & 5 & Monosomy 6 & $40 \%$ \\
\hline & & \multirow[t]{6}{*}{ HBl3AA } & TE 1 & $5-7$ & Euploid & \\
\hline & & & TE 2 & 10 & Nullisomy X, Y & $10 \%$ \\
\hline & & & \multirow[t]{4}{*}{$\mathrm{ICM}+\mathrm{TE}$} & \multirow[t]{4}{*}{10} & Trisomy 6 & $60 \%$ \\
\hline & & & & & \begin{tabular}{|l|} 
Trisomy 11 \\
\end{tabular} & $40 \%$ \\
\hline & & & & & Monosomy 13 & $60 \%$ \\
\hline & & & & & Nullisomy X, Y & $40 \%$ \\
\hline \multirow[t]{8}{*}{4} & \multirow[t]{8}{*}{$605 \times 100$ e4 } & $\mathrm{Bl} 3 \mathrm{AB}$ & PGT-A & 5 & Trisomy 2 & $40 \%$ \\
\hline & & & & & Trisomy 9 & $40 \%$ \\
\hline & & HBl6AB & TE 1 & 5 & Trisomy 2 & $20 \%$ \\
\hline & & & & & Trisomy 9 & $20 \%$ \\
\hline & & & TE 2 & 7 & Trisomy 2 & $40 \%$ \\
\hline & & & & & Trisomy 9 & $40 \%$ \\
\hline & & & $\mathrm{ICM}+\mathrm{TE}$ & 7 & Trisomy 2 & $30 \%$ \\
\hline & & & & & Trisomy 9 & $30 \%$ \\
\hline 5 & $605 \times 100 \mathrm{e} 8$ & $\mathrm{Bl} 2 \mathrm{AB}$ & PGT-A & 5 & Trisomy 8 & $70 \%$ \\
\hline & & & & & \begin{tabular}{|l|} 
Trisomy 12 \\
\end{tabular} & $70 \%$ \\
\hline & & & & & \begin{tabular}{|l} 
Trisomy 16 \\
\end{tabular} & $70 \%$ \\
\hline & & & & & Monosomy 6 & $40 \%$ \\
\hline & & & & & Monosomy 7q & $40 \%$ \\
\hline & & HBl6AB & TE 1 & $5-10$ & Monosomy 6 & $20 \%$ \\
\hline & & & & & Monosomy Xq & $40 \%$ \\
\hline & & & TE 2 & $5-10$ & Trisomy 8 & $30 \%$ \\
\hline & & & & & \begin{tabular}{|l|} 
Trisomy 12 \\
\end{tabular} & $30 \%$ \\
\hline & & & & & Trisomy 16 & $30 \%$ \\
\hline & & & & & Monosomy Xq & $20 \%$ \\
\hline & & & $\mathrm{ICM}+\mathrm{TE}$ & 15 & Trisomy 21 & $30 \%$ \\
\hline & & & & & Trisomy 4p & $30 \%$ \\
\hline & & & & & Monosomy 6q & $60 \%$ \\
\hline & & & & & Monosomy Xq & $50 \%$ \\
\hline 6 & $597 x 88$ e18 & Bl2AA & PGT-A & 5 & Trisomy 13 & $60 \%$ \\
\hline & & HBl6AA & TE 1 & $5-10$ & Euploid & \\
\hline & & & TE 2 & $5-10$ & Monosomy 13 & $20 \%$ \\
\hline & & & $\mathrm{ICM}+\mathrm{TE}$ & 15 & Monosomy 13 & $10 \%$ \\
\hline
\end{tabular}


However, it is probable that the nondisjunction occurred later than in embryo No. 2, because embryo No. 3 has a euploid cell line (TE 1) and a line diploid for chromosome 6 (TE 2). Yet, as in the previous case, an overall karyotype destabilization could be suspected with probable aneuploidy for other chromosomes not found in the first sample. The probability of giving birth to a healthy child with monosomy 6 detected in PGT-A sample in definite proportion of its cells was negligible and the embryo would not be recommended for transfer.

Embryo 605x100 e4 (No. 4) was a true mosaic since trisomy for chromosomes 2 and 9 was found in all samples from this embryo, although in different proportions. The stage of its origin is difficult to pinpoint, but it could possibly be a result of multipolar mitosis. Chromosome nondisjunction occurred rather early as the resulted blastocyst contained cells with different chromosomal constitution. It should be emphasized that mosaicism on trisomy 2 is exclusively tissue-specific and was detected only in extraembryonic mesoderm cells during prenatal diagnostics (Griffin 1996; Wolstenholme et al. 1994). There is only one report which describes cases of prenatal diagnosis of acardiac twin pregnancy with mosaic trisomy 2 (Blaicher et al. 2000). Full and mosaic trisomy 9 is often detected in spontaneous abortion, but it is sublethal (Baranov, Kuznetsova 2007). Thus the probability of becoming pregnant after the transfer of an embryo with simultaneously mosaic trisomy 2 and 9 seems very low.

Embryo 605x100 e8 (No. 5) contained aneuploid cells with imbalances in the entire chromosomes or their arms. Such anomalies are indicative of karyotype destabilization through mitotic divisions and mitotic recombination in centromeric regions of chromosomes (Giunta, Funabiki 2017). All these chromosomal anomalies could occur during early cleavage divisions (Daughtry, Chavez 2016). The probability of becoming pregnant after the embryo transfer is low.

Embryo 597x88 e18 (No. 6) was marked with chromosome 13 trisomy in $40 \%$ of its cells. Analysis of the sample from different parts of the embryo also showed monosomy 13 (reciprocal mosaic aneuploidy) and euploid cells, indicating its origin from mitotic nondisjunction at cleavage and predominant selection of monosomy clone.

The first article about the birth of a healthy child with a normal karyotype as a result of transferring an embryo with mosaic TE was published in 2015 (Greco et al. 2015). The number of relevant publications on the transfer of embryos with mosaicism revealed by PGT-A detected by the NGS method is increasing (Munne et al. 2017; Kushnir et al. 2018; Victor et al. 2019). Hereby, transfer of embryos with mosaic TE can give rise to pregnancy and result in the birth of a child with a euploid karyotype. Nevertheless, the rate of successful pregnancies is lower compared to that following the transfer of euploid embryos (Kushnir et al. 2018).

The trend to transfer mosaic embryos gradually expands as the efficiency of prenatal testing for chromosome imbalances steadily increases due to further improvements of PGT-A techniques (Sachdev et al. 2016; Victor et al. 2019). It is obvious that the transfer of mosaic embryos should be justified providing the absence of euploid embryos for transfer in the same couple. Our data indicate that the proportion of aneuploid cells in biopsy taken for PGT-A analysis does not necessarily reflect the true chromosomal status of the whole embryo and cannot be extrapolated to that in ICM cells. Meanwhile, our preliminary results indicate that if a mosaic chromosomal imbalance was detected in blastocyst, the probability of an euploid chromosome set in other parts is low. Consequently, mosaic embryo transfers should be considered with caution. Clinical recommendation for embryo transfer describes the requirements on prioritizing the transfer of mosaic embryos respective of PGT-A results (PGDIS position statement... 2019). The main idea of the recommendation is that the decision regarding the transfer should be taken respectively of the level of mosaicism and the data on the effects of the particular chromosome (chromosomal region) on prenatal and postnatal development (Grati 2014). Our data revealed that mosaic rate in the samples containing TE adjacent to ICM tends to increase, which may have physiological significance for implantation. Further comparative studies focused on the concordance of mosaicism level of and the type of chromosomal abnormalities detected in different parts of preimplantation human embryos will improve clinical recommendation for embryo transfer.

\section{Conflict of interest statement}

The authors have declared that no competing interests exist.

\section{Acknowledgments}

We are grateful to Chairman of the Russian Association for Human Reproduction, Prof. V. S. Korsak for actively supporting the development of the most advanced methods of preimplantation genetic research in Russia. We thank Dr. A. S. Komissarov for his assistance in the quality control of the raw reads for sequencing results. 


\section{References}

Baranov, V. S., Kuznetsova, T. V. (2007) Tsitogenetika embrionalnogo razvitiya cheloveka [Human embryonic development cytogenetics]. Saint Petersburg: N-L Publ., 640 p. (In Russian)

Blaicher, W., Repa, C., Schaller, A. (2000) Acardiac twin pregnancy: Associated with trisomy 2: Case report. Human Reproduction, vol. 15, no. 2, pp. 474-475. PMID: 10655326. DOI: 10.1093/humrep/15.2.474 (In English)

Campbell, S., Mavrides, E., Prefumo, F. et al. (2001) Prenatal diagnosis of mosaic trisomy 8 in a fetus with normal nuchal translucency thickness and reversed end-diastolic ductus venosus flow. Ultrasound in Obstetrics E Gynecology, vol. 17, no. 4, pp. 341-343. PMID: 11339193. DOI: 10.1046/j.1469-0705.2001.00393.x (In English)

Daughtry, B. L., Chavez, S. L. (2016) Chromosomal instability in mammalian pre-implantation embryos: Potential causes, detection methods, and clinical consequences. Cell and Tissue Research, vol. 363, no. 1, pp. 201-225. PMID: 26590822. DOI: 10.1007/s00441-015-2305-6 (In English)

Gardner, D. K., Schoolcraft, W. B. (1999) In vitro culture of human blastocyst. In: R. Jansen, D. Mortimer (eds.). Towards reproductive certainty: Fertility and genetics beyond. New York: The Parthenon Publ., pp. 377-388. (In English)

Gardner, R. J. M., Amor, D. J. (2018) Gardner and Sutherland's chromosome abnormalities and genetic counseling. $5^{\text {th }}$ ed. New York: Oxford University Press, 784 p. (In English)

Giunta, S., Funabiki, H. (2017) Integrity of the human centromere DNA repeats is protected by CENP-A, CENP-C, and CENP-T. Proceedings of the National Academy of Sciences of the United States of America, vol. 114, no. 8, pp. 1928-1933. DOI: 10.1073/pnas.1615133114 (In English)

Grati, F. R. (2014) Chromosomal mosaicism in human feto-placental development: Implications for prenatal diagnosis. Journal of Clinical Medicine, vol. 3, no. 3, pp. 809-837. PMID: 26237479. DOI: 10.3390/jcm3030809 (In English)

Greco, E., Minasi, M. G., Fiorentino, F. (2015) Healthy babies after intrauterine transfer of mosaic aneuploid blastocysts. The New England Journal of Medicine, vol. 373, no. 21, pp. 2089-2090. PMID: 26581010. DOI: 10.1056/NEJMc1500421 (In English)

Griffin, D. K. (1996) The incidence, origin, and etiology of aneuploidy. International Review of Cytology, vol. 167, pp. 263-296. PMID: 8768496. DOI: 10.1016/s0074-7696(08)61349-2 (In English)

Korsak, V. S. (ed.) (2019) Rukovodstvo po klinicheskoj ehmbriologii [Clinical embryology guide]. Moscow: SIMK Publ., 224 p. (In Russian)

Kushnir, V. A., Darmon, S. K., Barad, D. H., Gleicher, N. (2018) Degree of mosaicism in trophectoderm does not predict pregnancy potential: A corrected analysis of pregnancy outcomes following transfer of mosaic embryos. Reproductive Biology and Endocrinology, vol. 16, no. 1, article 6. PMID: 29373974. DOI: 10.1186/ s12958-018-0322-5 (In English)

Munné, S., Blazek, J., Large, M. et al. (2017) Detailed investigation into the cytogenetic constitution and pregnancy outcome of replacing mosaic blastocysts detected with the use of high-resolution next-generation sequencing. Fertility and Sterility, vol. 108, no. 1, pp. 62-71. PMID: 28579407. DOI: 10.1016/j.fertnstert.2017.05.002 (In English)

PGDIS position statement on the transfer of mosaic embryos in preimplantation ganetic testing for aneuploidy (PGT-A). (2019) PGDIS (Preimplantation Genetics Diagnosis International Society). [Online]. Available from: http://pgdis.org/docs/newsletter_052719.pdf (accessed 12.08.2020). (In English)

Sachdev, N. M., Ribustello, L., Liu, E. et al. (2016) The rate of mosaic embryos from donor egg as detected by next generation sequencing (NGS) varies by IVF laboratory. Fertility and Sterility, vol. 106, no. 3, suppl., e156-e157. DOI: 10.1016/j.fertnstert.2016.07.463 (In English)

Taylor, T. H., Griffin, D. K., Katz, S. L. et al. (2016) Technique to "map" chromosomal mosaicism at the blastocyst stage. Cytogenetic and Genome Research, vol. 149, no. 4, pp. 262-266. DOI: 10.1159/000449051 (In English)

Victor, A. R., Tyndall, J. C., Brake, A. J. et al. (2019) One hundred mosaic embryos transferred prospectively in a single clinic: Exploring when and why they result in healthy pregnancies. Fertility and Sterility, vol. 111, no. 2, pp. 280-293. PMID: 30691630. DOI: 10.1016/j.fertnstert.2018.10.019 (In English)

Weissman, A., Shoham, G., Shoham, Z. et al. (2017) Chromosomal mosaicism detected during preimplantation genetic screening: Results of a worldwide web-based survey. Fertility and Sterility, vol. 107, no. 5, pp. 1092-1097. PMID: 28433368. DOI: 10.1016/j.fertnstert.2017.02.119 (In English)

Wolstenholme, J., Rooney, D. E., Davison, E. V. (1994) Confined placental mosaicism, IUGR, and adverse pregnancy outcome: A controlled retrospective U.K. collaborative survey. Prenatal Diagnosis, vol. 14, no. 5, pp. 345-361. DOI: 10.1002/pd.1970140505 (In English) 